\title{
Biochemical and cultural characteristics of "JK" coryneforms
}

\author{
R BAYSTON, J HIGGINS \\ From the Department of Paediatric Surgery, Institute of Child Health, London
}

SUMMARY Antibiotic resistant coryneforms (group JK) have increasingly been reported as causes of serious sepsis in the immunosuppressed and in patients with implants. Their cultural and biochemical characteristics were examined in an attempt to provide a simple scheme for their recognition in the clinical laboratory. Their susceptibilities to a range of antimicrobials were determined, and an enriched selective medium was developed for their isolation from normally non-sterile sites. The JK coryneforms fell into a fairly homogeneous group, producing colonial morphology and biochemical profiles identical with reference strains, which allowed their recognition and differentiation from other coryneforms. All strains were resistant to penicillin and susceptible to vancomycin, but there was considerable variation with respect to other antimicrobials. There is scope for further rationalisation of biochemical tests for the recognition of these organisms.

The first major report of infections caused by coryneforms, other than corynebacterium diphtheriae, was by Johnson and Kaye, ${ }^{1}$ who reviewed fifty two published cases. Six years later Hande $e a^{2}$ reported four infections due to "a new species of corynebacterium." Three patients with leukaemia had septicaemia and one had ventriculoatrial shunt infection. The organisms were resistant to penicillin, aminoglycosides, and, in one case, rifampicin. Pearson et $\mathrm{l}^{3}$ reported 12 cases in two years in patients undergoing bone marrow transplantation. Again, all strains were multiresistant. In the same year Riley et $\mathrm{al}^{4}$ collected and examined ninety five strains of multiresistant coryneforms and proposed that they be referred to as "group JK" after Johnson and Kaye.

Since then, Gronemeyer ${ }^{5}$ has reported a case of infection of a pacemaker generator and Murray et $a l^{6}$ have described 18 cases of prosthetic valve endocarditis. Gill et al $^{7}$ reported seven more cases of bacteraemia on an oncology unit and Finger et $\mathrm{al}^{8}$ reported 13 similar cases, including patients on an intensive care unit. Hoffman' ${ }^{9}$ reported a fatal case of meningitis in a patient with lymphoma. Three cases of peritonitis in patients receiving continuous ambulatory peritoneal dialysis have also been described (Pierrard et al, ${ }^{10}$ Altwegg et al ${ }^{11}$ ). More recently, four patients with granulocytopaenia ${ }^{12}$ and one with aplastic anaemia ${ }^{13}$ were reported as having septicaemia due to JK coryneforms. Many more cases probably

Accepted for publication 30 January 1986 go unreported, or are reported to the Communicable Disease Surveillance Centre as "diphtheroids". The organisms present the routine clinical laboratory with difficulties in isolation and identification, growing slowly on ordinary media and producing positive biochemical results only in the presence of serum or after several days' incubation. A further question is that of their natural habitats, as well as their importance when isolated from normal sites as part of surveillance of patients nursed in protective isolation. Tomkins, ${ }^{14}$ Finger et al, ${ }^{8}$ and Wichman et al ${ }^{15}$ conducted surveys using selective media. Unfortunately, media containing antimicrobials such as cephalosporins or aminoglycosides were used, and these are likely to yield only those strains resistant to these agents, while non-selective media will fail to isolate JK coryneforms due to overgrowth of other commensals. ${ }^{14}$

We therefore decided to investigate the cultural and biochemical characteristics of a collection of clinical isolates with the aim of allowing their rapid recognition in the clinical laboratory. We also investigated various selective and enrichment agents with a view to developing a medium that could be used in surveillance studies.

\section{Material and methods}

\section{SOURCES OF ISOLATES}

Many coryneforms were donated by microbiologists in the United Kingdom, often after being reported in either the Communicable Disease Report or the Com- 
municable Diseases (Scotland) Report. Others were isolated by us. Three strains had been identified by the Centers for Disease Control (CDC) Atlanta, as JK coryneforms. A total of 52 strains were included.

\section{CULTURAL CHARACTERISTICS}

Strains were inoculated on to Columbia blood agar (Lab M Ltd UK) and incubated aerobically at $37^{\circ} \mathrm{C}$ for 48 hours. Their microscopic and colonial morphologies and catalase reaction were noted. Subsequently, all strains were additionally incubated anaerobically on Columbia blood agar and in thioglycollate broth supplemented with $1 \%$ Tween 80 . The plates were incubated in an aerobic jar with $80 \%$ nitrogen, $10 \%$ hydrogen, and $10 \%$ carbon dioxide, and a palladium aluminium catalyst. A plate inoculated with Pseudomonas aeruginosa was used as a control.

\section{ENRICHMENT AGENTS}

Strains were grown on Columbia blood agar, nutrient agar, brain heart infusion agar, and tryptone soya agar (Lab M United Kingdom). Each of these was used plain and supplemented with one of the following: horse blood $7 \%$, whole, lysed, and heated; tributyrin $1 \%$; and Tweens $20,40,60,80$, and 85 , all at $1 \%$. Further tests were then carried out using brain heart infusion agar to determine the optimum concentrations of Tween 80 , using $0.05 \%, 0.1 \%, 0.5 \%$, $1.0 \%$, and $2.0 \%$. Plates were incubated for 48 hours at $37^{\circ} \mathrm{C}$ and the number and size of the colonies noted and compared.

\section{SELECTIVE AGENTS}

Brain heart infusion agar containing $1 \%$ Tween 80 was supplemented with one of the following: potassium tellurite $0.02 \%, 0.03 \%$, and $0.04 \%$; polymyxin B sulphate; and mupirocin (pseudomonic acid). The optimum concentrations were determined by inoculation of the enriched medium containing the selective agent with a range of Gram negative and Gram positive organisms (Table 1).

\section{IDENTIFICATION TESTS}

To test as many substrates as possible within the constraints of the study and to cover the likely range of tests each coryneform was inoculated into both API Staph and API Strep (API Laboratory Products Ltd). API Staph dilution fluid supplemented with $0.2 \mathrm{ml}$ sterile rabbit serum was used for both to suspend the growth from a whole blood agar plate in strains producing small colonies. Enough of the large colony producers was used to give a turbidity equal to No 4 on the MacFarland scale. Two drops of API Strep indicator were added to the carbohydrate cupules in the API Strep strip and the tests were then incubated for 48 hours at $37^{\circ} \mathrm{C}$ before adding reagents and reading results.

\section{SUSCEPTIBILITY TO ANTIMICROBIALS}

Strains were tested for susceptibility to 14 antimicrobials using a modified Stokes method and a rotary inoculator. The medium used was Diagnostic Sensitivity Test agar (Oxoid United Kingdom) supplemented with lysed horse blood. Susceptibility to methicillin was tested on Columbia agar plates containing polyvinylpyrrolidone, ${ }^{16} 1 \%$ Tween 80 , and $12.5 \mathrm{mg} / 1$ methicillin, and incubated overnight at $30^{\circ} \mathrm{C}$. Results were converted to a numerical antibiogram ${ }^{17}$ by scoring for resistance (Table 2 ).

\section{Results}

CULTURAL CHARACTERISTICS

After 48 hours on blood agar strains could be allotted to one of two main groups, depending on colonial

Table 1 Action of potentially selective agents against coryneforms and other organisms

\begin{tabular}{|c|c|c|c|c|c|c|c|}
\hline \multirow[t]{2}{*}{ Organism } & \multirow{2}{*}{$\begin{array}{l}\text { Control } \\
B H I+T 80\end{array}$} & \multicolumn{3}{|c|}{ Potassium tellurite (\%) } & \multirow{2}{*}{$\begin{array}{l}\text { Polymyxin B } \\
(8 \mathrm{mg} / \mathrm{l})\end{array}$} & \multirow{2}{*}{$\begin{array}{l}\text { Mupirocin } \\
\text { (I mg/l) }\end{array}$} & \multirow{2}{*}{$\begin{array}{l}\text { Selective } \\
\text { enriched } \\
\text { medium }\end{array}$} \\
\hline & & 0.02 & 0.03 & 0.04 & & & \\
\hline JK & + & - & - & - & + & + & + \\
\hline Clostridium xerosis & + & - & - & - & + & + & + \\
\hline Clostridium pseudodiphtheriticum & + & - & - & - & + & + & + \\
\hline Enterococcus & + & + & + & - & + & + & + \\
\hline Staphylococcus aureus & + & + & + & + & + & - & - \\
\hline Staphylococcus aureus (methicillin resistant) & + & + & + & + & + & - & - \\
\hline Staphylococcus epidermidis & + & \pm & - & - & - & - & - \\
\hline Escherichia coli & + & $\overline{-}$ & - & - & - & + & - \\
\hline Proteus & + & - & - & - & + & + & + \\
\hline Pseudomonas aeruginosa & + & - & - & - & - & + & - \\
\hline Klebsiella pneumoniae & + & - & - & - & - & + & - \\
\hline Candida albicans & + & + & + & + & + & + & + \\
\hline
\end{tabular}

BHI + T80 = Brain heart infusion agar with $1 \%$ Tween 80 .

$+=$ Growth; $-=$ no growth; $\pm=$ minimal growth. 
Table 2 Derivation of numerical antibiogram

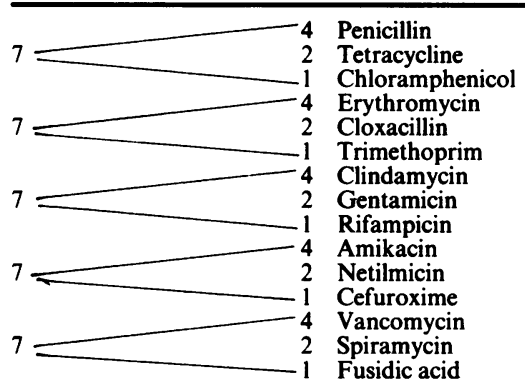

Susceptibility scores $\mathbf{0}$, resistance scores as shown

diameter. The large colony strains were further subdivided for the purpose of this study into three types and the small colony strains into two types (Table 3 ). Reference strains, which had been identified as JK coryneforms by Centers for Disease Control, fell into colony type D. Colony type E strains consisted of those small colony types that were not type $D$ and were, therefore, a heterogeneous group. All strains were non-haemolytic on horse blood, non-motile at room temperatures and $37^{\circ} \mathrm{C}$, and catalase positive. They were all Gram positive rods or cocco-bacilli on microscopy, though not always displaying the typical arrangement in pallisades. All strains failed to grow anaerobically on blood agar, and when incubated in thioglycollate broth supplemented with $1 \%$ Tween 80 they grew only in the top 1-2 mm. Two strains were of colony type A, one of type B, eight of type C, 38 of type $\mathrm{D}$, and three of type $\mathrm{E}$.

\section{ENRICHMENT AGENTS}

Growth on brain heart infusion agar was superior to that on Columbia agar, nutrient agar, and tryptone soya agar, as determined by colony size. The number of colonies recovered did not differ appreciably. The addition of horse blood in any form did not enhance growth. Egg yolk did not enhance growth and was inhibitory to some strains, and tributyrin was also not beneficial.

Although the growth of some coryneforms was enhanced by the addition of Tweens 20,40 , and 60 at a final concentration of $1 \%$, these proved inhibitory to the small colony types D and E. A $1 \%$ concentration of Tweens 80 and 85 , however, greatly enhanced growth, with Tween 80 being superior to Tween 85 . Growth enhancement by Tween 80 was still greater on brain heart infusion agar. In view of this the optimal concentration of Tween 80 in this medium was determined and was found to be $1 \%$. The final enrichment agar consisted of brain heart infusion agar supplemented with $1 \%$ Tween 80 .

When grown on this medium for $\mathbf{4 8}$ hours colonies of the certified JK coryneforms appeared as yellowish, smooth, convex, entire, $2-3 \mathrm{~mm}$ in diameter, and surrounded by a wide halo of hydrolysis products of Tween 80 , both in the agar and on its surface. This halo became much more pronounced on incubation for a further 24 hours. All strains of colony type D closely resembled the certified JK strains. The enriched medium could not, however, be used to differentiate between colony types as all grew very well, so that differences in size were no longer apparent, and differentiation was carried out using Columbia blood agar (Figure).

\section{SELECTIVE AGENTS}

Table 1 shows the inhibitory effects of the agents tested against a range of organisms. All concentrations of potassium tellurite tested were inhibitory to coryneforms, though this effect was shown only in the presence of Tween 80 . Polymyxin B sulphate at a concentration of $8 \mathrm{mg} / \mathrm{l}$ permitted the growth of coryneforms while inhibiting Gram negative rods, with the exception of Proteus. Similarly, the coryneforms were resistant to $1 \mathrm{mg} / 1$ of mupirocin, which was sufficient to inhibit staphylococci. Faecal streptococci were not inhibited, but in practice these could be distinguished by colonial appearance and catalase reaction. The final selective enriched medium consisted of brain heart infusion agar with $1 \%$ Tween $80,8 \mathrm{mg} / 1$ polymyxin B sulphate, and $1 \mathrm{mg} / \mathrm{l}$ mupirocin.

\section{IDENTIFICATION TESTS}

Table 4 shows the numerical profiles derived from the test strips: these are grouped according to colony type. Table 5 shows a short profile derived from a limited number of substrates.

All strains except 7308 (colony type C) gave a positive Voges Proskauer reaction. All gave a positive reaction for hippurate hydrolase and leucine ary-

Table 3 Colonial types of coryneforms on Columbia blood agar $\left(37^{\circ} \mathrm{C}, 48\right.$ hours)

\begin{tabular}{|c|c|c|c|}
\hline & Type & Diameter ( $\mathrm{mm}$ ) & Description \\
\hline $\begin{array}{l}\text { Large colony types } \\
\text { Small colony types }\end{array}$ & $\begin{array}{l}\text { A } \\
\text { B } \\
\text { C } \\
\text { D } \\
\text { E }\end{array}$ & $\begin{array}{l}2-3 \\
2 \\
2 \cdot 5 \\
0 \cdot 5-1 \\
<0 \cdot 5-1\end{array}$ & $\begin{array}{l}\text { White, rough, dry, matt, crenated } \\
\text { White/greenish, matt, entire } \\
\text { Greenish, domed, glossy } \\
\text { Glossy, white or grey, domed } \\
\text { Dry, flat, often crenated }\end{array}$ \\
\hline
\end{tabular}



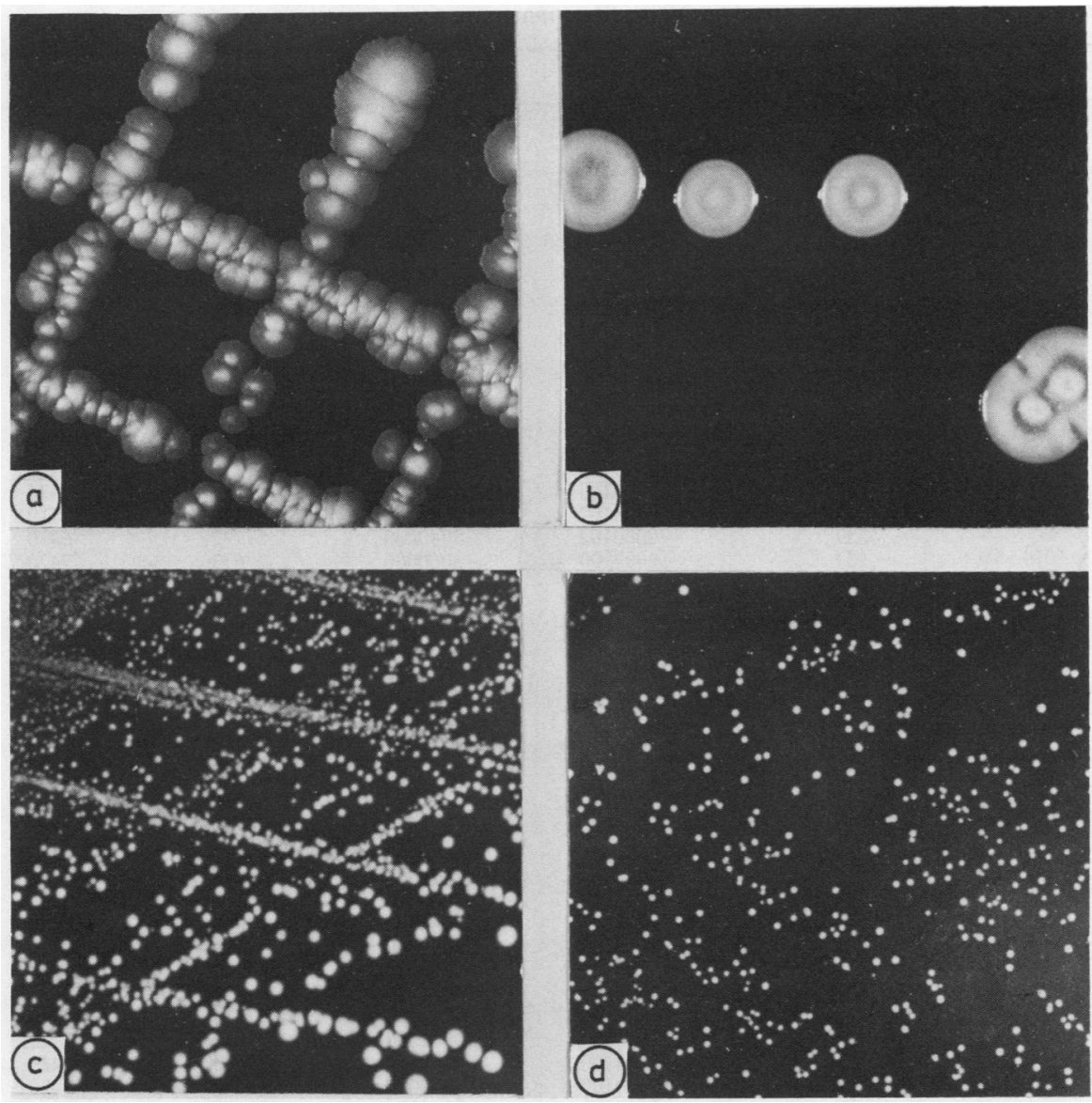

Figure (a) Large colony coryneform; (b) large colony coryneform; (c) small colony coryneform, colony type D (JK); (d) small colony coryneform, colony type E. All were grown on Columbia blood agar for 48 hours.

lamidase and, with the exception of one strain of colony type $\mathrm{D}$, for alkaline phosphatase. Typical JK coryneforms, exemplified by the Centers for Disease Control certified strains, were found to be of colony type D and to give positive reactions for Voges Proskauer, leucine arylamidase, hippurate hydrolase, and alkaline phosphatase, and negative reactions for nitrate reduction and pyrrolidonylarylamidase; they failed to acidify maltose or fructose. Some stains acidified glucose and a few hydrolysed urea. The short profile was based on reactions for the above tests. The typical JK coryneforms profiles were: API Staph 200 4100; API Strep 306 2000, short profile 7420 , colony type D.

\section{SUSCEPTIBILITY TO ANTIMICROBIALS}

The results were converted into numerical antibiograms (Table 2), and these profiles are shown in
Table 4 . The colony type D strains may be seen to show resistance to more antimicrobials than other colony types, with a few exceptions among colony types $A$ and $C$. Eight large colony strains were found to be susceptible to penicillin. Most strains were resistant to methicillin. Only seven colony type D strains were susceptible to cefuroxime. Twenty eight of the thirty eight colony type D strains were susceptible to rifampicin, and all were susceptible to vancomycin.

\section{Discussion}

Organisms considered to be JK coryneforms generally grew poorly and slowly on ordinary noninhibitory media. The very small grey-white colonies usually appeared only after at least forty eight hours' incubation. Various supplemented media have been used, such as that described by Finger et al, ${ }^{8}$ which 
Table 4 Results of colony typing, biochemical profiles, and antibiograms for large colony types

\begin{tabular}{|c|c|c|c|c|c|}
\hline No & Colony type & API staph & API strep & Antibiogram & "Short profile" \\
\hline $\begin{array}{l}7104 \\
5944 \\
7580 / 4 \mathrm{~B} \\
7308 \\
7576 / 2 \\
7580 / 1 \mathrm{a} / \mathrm{b} \\
7580 / 4 \mathrm{c} \\
7580 / 2 \\
7580 / 3 \\
7294 \\
7295 \\
7579 / 2 \\
5937 \\
5936 \\
7427 \\
7573 / 5 \\
7353 \\
7394 / 1 \\
6649 \\
6648 \\
7573 / 4 \\
5938 \\
7209 \\
6651 \\
6136 \\
6652 \\
6542 \\
6653 \\
6543 \\
6960 \\
6541 \\
6650 \\
6540 \\
7210 \\
7071 \\
7065 \\
7063 \\
6539 \\
6536 \\
7275 \\
7019 \\
7579 / 5 \\
7309 \\
7576 / 4 \\
7573 / 1 \\
757735 \\
7576 / 3 \\
7016 \\
7271 \\
7272 \\
7307 \\
7276 \\
\end{array}$ & $\begin{array}{l}\text { A } \\
\text { A } \\
\text { B } \\
\text { C } \\
\text { C } \\
\text { C } \\
\text { C } \\
\text { C } \\
\text { C } \\
\text { C } \\
\text { C } \\
\text { D } \\
\text { D } \\
\text { D } \\
\text { D } \\
\text { D } \\
\text { D } \\
\text { D } \\
\text { D } \\
\text { D } \\
\text { D } \\
\text { D } \\
\text { D } \\
\text { D } \\
\text { D } \\
\text { D } \\
\text { D } \\
\text { D } \\
\text { D } \\
\text { D } \\
\text { D } \\
\text { D } \\
\text { D } \\
\text { D } \\
\text { D } \\
\text { D } \\
\text { D } \\
\text { D } \\
\text { D } \\
\text { D } \\
\text { D } \\
\text { D } \\
\text { D } \\
\text { D } \\
\text { D } \\
\text { D } \\
\text { D } \\
\text { D } \\
\text { D } \\
\text { E } \\
\text { E } \\
\text { E }\end{array}$ & $\begin{array}{l}6306100 \\
0006100 \\
6704100 \\
6004000 \\
6310150 \\
6310150 \\
6704100 \\
0000100 \\
0004002 \\
0006102 \\
0006102 \\
2004100 \\
2004100 \\
2004100 \\
2004100 \\
2004100 \\
2004100 \\
0004102 \\
0000102 \\
2004100 \\
2004100 \\
2004100 \\
2004100 \\
0004100 \\
2004100 \\
2004100 \\
0004102 \\
2004100 \\
0004000 \\
2004100 \\
0004100 \\
2004100 \\
2004100 \\
0004100 \\
0004100 \\
2004100 \\
2004100 \\
2004100 \\
2004100 \\
2004100 \\
2004100 \\
2004100 \\
2000100 \\
2004100 \\
2004100 \\
2004100 \\
2004100 \\
2004100 \\
2004100 \\
4206101 \\
6106010 \\
6314110\end{array}$ & $\begin{array}{l}3062003 \\
3062000 \\
3062003 \\
2062000 \\
3162013 \\
3162013 \\
3062003 \\
1160000 \\
3060000 \\
3160000 \\
3160000 \\
3062000 \\
3062000 \\
3062000 \\
3062000 \\
3062000 \\
3060000 \\
2060003 \\
3040000 \\
3060000 \\
3062000 \\
3062002 \\
3062000 \\
3062000 \\
3062000 \\
3062000 \\
3060000 \\
3062000 \\
3060000 \\
3062000 \\
3062000 \\
3060000 \\
3062000 \\
3060000 \\
3060000 \\
3062000 \\
3060000 \\
3062000 \\
3062010 \\
3060000 \\
3062000 \\
3060100 \\
3060020 \\
3062010 \\
3062000 \\
3060000 \\
3062000 \\
3062000 \\
3062010 \\
2060400 \\
3060000 \\
2062013\end{array}$ & $\begin{array}{l}17000 \\
55662 \\
03000 \\
01000 \\
03000 \\
03000 \\
03000 \\
77462 \\
57412 \\
01000 \\
01000 \\
77402 \\
77413 \\
77413 \\
77672 \\
57773 \\
77773 \\
53010 \\
57772 \\
77673 \\
57773 \\
77413 \\
77672 \\
77773 \\
77673 \\
77673 \\
77772 \\
77672 \\
77673 \\
77403 \\
73270 \\
77673 \\
57672 \\
77773 \\
77413 \\
47402 \\
77672 \\
57672 \\
776772 \\
77673 \\
77673 \\
73000 \\
43000 \\
77673 \\
77773 \\
57773 \\
43000 \\
77702 \\
43000 \\
20000 \\
30000 \\
35402\end{array}$ & $\begin{array}{l}7561 \\
7500 \\
7461 \\
7721 \\
7661 \\
7661 \\
7461 \\
5600 \\
7400 \\
7710 \\
7710 \\
7420 \\
7420 \\
7420 \\
7420 \\
7420 \\
7420 \\
7410 \\
6410 \\
7420 \\
7420 \\
7420 \\
7420 \\
7400 \\
7420 \\
7420 \\
7410 \\
7420 \\
7400 \\
7420 \\
7410 \\
7420 \\
7420 \\
7400 \\
7400 \\
7420 \\
7420 \\
7420 \\
7420 \\
7420 \\
7420 \\
7420 \\
7420 \\
7420 \\
7420 \\
7420 \\
7420 \\
7420 \\
7420 \\
7441 \\
7521 \\
7461\end{array}$ \\
\hline
\end{tabular}

Table 5 Derivation of "short profile"

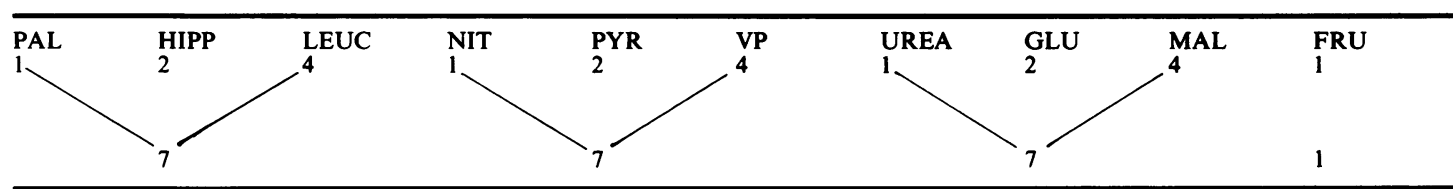

Results are scored 0 when negative, and as shown when positive.

PAL = Alkaline phosphatase; HIPP = Hippurate hydrolase; LEUC = Leucine arylamidase; NIT = Nitrate reduction; PYR = Pyrrolidonylarylamidase; VP = Voges-Proskauer; UREA = Urease production; GLU = Acidification of glucose; MAL = Acidification of maltose; FRU = Acidification of fructose. 
contained tryptose agar, histidine, egg yolk, Tween 80 $(3 \%)$, sodium thiosulphate, and glycerol, along with broad spectrum antibiotics. Jadeja et al $^{18}$ used brain heart infusion agar supplemented with $5 \%$ rabbit serum, but they dealt only with laboratory stock strains. Our strains showed a distinct tendency to become less demanding on storage and subculture, though the difference in growth on blood agar and brain heart infusion agar containing Tween 80 was still considerable. The inclusion of broad spectrum antibiotics such as aminoglycosides and cephalosporins is likely to lead to failure to isolate certain strains. Twelve of the thirty eight typical JK coryneforms in our series were susceptible to gentamicin on disc testing. Tomkins $\mathrm{et} \mathrm{al}^{14}$ found that failure to include a cephalosporin in their selective medium permitted overgrowth of any JK coryneforms by coagulase negative staphylococci, but seven of our JK strains proved to be susceptible to cefuroxime.

This problem was one reason why therapeutically applicable antimicrobials were avoided in the selective medium reported here. All coryneforms tested so far in this laboratory seem to be intrinsically resistant to polymyxin B and mupirocin, and the use of these two agents in an ecological survey, or for specimens from "normal flora" sites, would be expected to lead to isolation of both susceptible and multiresistant strains. The use of brain heart infusion agar with $1 \%$ Tween 80 is recommended for routine isolation of $\mathrm{JK}$ coryneforms on solid media from normally sterile sites, or from catheters. Polymyxin B and mupirocin should be added for sites not normally sterile, such as skin and mucous membranes. Nalidixic acid could be added if Proteus is likely to be troublesome. It may also be helpful to supplement blood culture media with Tween 80 for use in the immunosuppressed patient or those otherwise considered to be at risk from JK coryneform infections.

Corynebacteria are usually described as being "aerobic, facultative." 19 Some authors do not state the oxygen requirement of their isolates, but those who do find that they are strict aerobes. ${ }^{2} 38132021$ Only two authors, however, have paid much attention to this. Hande $e a^{2}{ }^{2}$ went on to attempt to grow their strains in supplemented thioglycollate broth and found only surface growth, as is reported here. Downie et al ${ }^{13}$ were able to grow their isolate only in the aerobic bottles of blood cultures and commented that this caused a delay of recognition of its clinical importance. All our strains of coryneforms were found to be strict aerobes.

The use of API Strep for identification of JK coryneforms was suggested by Kelly et al. ${ }^{22}$ When examining large numbers of biochemical characteristics on a large group of organisms with the usual time constraints, systems such as API Staph and API Strep are invaluable. It is inevitable, however, that not all the tests will be of value. The small colony type coryneforms are relatively biochemically inactive, and most carbohydrates were not attacked, the only useful ones being glucose, fructose, and maltose. The "short profiles" were compiled from those tests that were considered to be helpful, and if the use of this, or a similar group of tests, becomes accepted then manufacturers might be persuaded to consider the production of a more relevant test strip. Alternatively, a range of laboratory made substrates in microtitre trays could be considered. Generally, the profiles reported here correspond to those already published, but with some exceptions. Comparing the results with those of Riley et al, ${ }^{4}$ shows that the biggest discrepancy lies in the Voges-Proskauer test. All our strains were Voges Proskauer positive, whereas all of Riley's were negative. This is most probably explained by the different test substrates. The Voges Proskauer test determines the ability to produce acetoin from glucose, but in the API system the substrate is pyruvate, which represents a starting point further into the pathway. In addition, eight of the JK coryneforms listed in Table 2 failed to acidify glucose, whereas all of Riley's strains were positive in this test. Similarly, none of the colony type of D JK strains acidified maltose or fructose, whereas $44 \%$ and $35 \%$, respectively, of Riley's strains were positive: this probably reflects differences between test conditions, which in turn can affect the rates of reactions to change results read in a defined time scale.

The JK coryneforms have been described several times as a new species of corynebacterium, but recently reports of their similarity to biovars I to VI of $C$ genitalium and biovar $\mathrm{C} 6$ of $C$ pseudogenitalium have appeared. ${ }^{23}$ These organisms are found in the urethra, and in the case of $C$ genitalium, are considered by some to be a cause of non-specific urethritis. ${ }^{24}$ They are obligate aerobes and produce colonies on blood agar, which are morphologically identical with JK coryneforms. Their biochemical reactions are also similar. Biovars II and IV of $C$ genitalium oxidise glucose, and biovar VI hydrolyses urea. Biovar C6 of $C$ pseudogenitalium oxidises fructose but not glucose. The strains reported in studies were multiresistant to antimicrobials and their growth was enhanced by Tween 80. These biovars of $C$ genitalium and $C$ pseudogenitalium might be synonymous with JK coryneforms. More chemotaxonomic investigations, however, are needed. We believe that coryneforms considered to be of clinical importance should be sent to reference experts for further study, but there is a considerable amount that the clinical laboratory can do to identify provisionally such strains. We hope that the observations reported here will help in the isolation and recognition of these strains. 
We are grateful to those microbiologists who kindly sent strains for study. JH was supported by a grant from Essex ASBAH.

\section{References}

${ }^{1}$ Johnson WD, Kaye D. Serious infections caused by diphtheroids. Ann NY Acad Sci 1970;174:568-76.

${ }^{2}$ Hande KR, Witebsky FG, Brown MS, et al. Sepsis with a new species of corynebacterium. Ann Intern Med 1976;85:423-6.

${ }^{3}$ Pearson TA, Braine HG, Rathburn HK. Corynebacterium species in oncology patients. $J A M A 1977 ; 238: 1737-40$.

${ }^{4}$ Riley PS, Hollis DG, Utter GB, Weaver RE, Baker CN. Characterisation and identification of 95 diphtheroid (group JK) cultures isolated from clinical specimens. $J$ Clin Microbiol 1979;9:418-24.

${ }^{5}$ Gronemeyer PS, Weissfeld AS, Sonnenwirth AC. Corynebacterium group JK bacterial infection of an epicardial pacemaker. Am J Clin Pathol 1980;74:838-42.

${ }^{6}$ Murray B, Karchmer W, Moellering R. Diphtheroid prosthetic valve endocarditis; a study of clinical features and infecting organisms. Am J Med 1980;69:838-48.

${ }^{7}$ Gill V, Manning C, Lamson M, Woltering P, Pizzo P. Antibiotic resistant group JK bacteria in hospitals. J Clin Microbiol 1981;13:474-7.

${ }^{8}$ Finger $\mathrm{H}$, von Koenig C-HW, Wichman S, Becker-Boost E, Drechsler HJ. Clinical significance of resistant corynebacteria group JK. Lancet 1983;i:538.

${ }^{9}$ Hoffman S, Ersgaard H, Justesen T, Friis H. Fatal meningitis with group JK corynebacterium in a leucopenic patient. Eur J Clin Microbiol 1983;2:213-5.

${ }^{10}$ Pierrard D, Lauwers S, Mouton M-C, Sennesael J, Verbeelen D. Group JK corynebacterium peritonitis in a patient undergoing continuous ambulatory peritoneal dialysis. J Clin Microbiol 1983;18:1011-4.

${ }^{11}$ Altwegg M, Zaruba K, von Gráevenitz A. Corynebacterium group JK. Peritonitis in patients on continuous ambulatory peritoneal dialysis. Klin Wochenschr 1984;62:793-4.

${ }^{12}$ Quinn J, Arnow P, Weil D, Rosenbluth J. Outbreak of JK diphtheroid infection associated with environmental contamination.
J Clin Microbiol 1984;19:668-71.

${ }^{13}$ Downie GW, Gill DS. Infection in an immunocompromised patient caused by "group JK" corynebacterium. J Infect 1984;8:262-3.

${ }^{14}$ Tomkins LS, Juffali F, Stamm WE. Use of a selective broth enrichment to determine the prevalence of multiply-resistant JK corynebacteria on the skin. J Clin Microbiol 1982;15:350-1.

${ }^{15}$ Wichman S, von Koenig C-HW, Becker-Boost E, Finger H. Isolation of Corynebacterium group JK from clinical specimens with a semi selective medium. J Clin Microbiol 1984;19:204-6.

${ }^{16}$ Bayston R. Use of polyvinylpyrrolidone in the testing of staphylococci for sensitivity to methicillin and cephradine. J Clin Pathol 1979;31:434-6.

${ }^{17}$ Bayston R. Bacteriological examination of removed cerebrospinal fluid shunts. J Clin Pathol 1983;36:987-90.

${ }^{18}$ Jadeja L, Feinstein V, le Blanc B, Bodey GP. Comparative in vitro activities of teichomycin and other antibiotics against JK diphtheroids. Antimicrob Agents Chemother 1983;24:145-6.

${ }^{19}$ Bergey's manual of determinative bacteriology. Eighth ed. Buchanan RE, Gibbons NE, ed. Baltimore: Williams and Williams, 1974.

${ }^{20}$ Smith RF. Characterisation of human cutaneous lipophilic diphtheroids. J Gen Microbiol 1969;55:433-43.

${ }^{21}$ von Koenig C-HW, Wichman S, Finger $\mathrm{H}$. Infections caused by corynebacterium Group JK. Zbl Bakt Hyg I Abt Orig A 1982:370-6.

${ }^{22}$ Kelly MC, Smith ID, Anstey RJ, Thornley JH, Rennie RP. Rapid identification of antibiotic resistant corynebacteria with the API 20S System. J Clin Microbiol 1984;19:245-7.

${ }^{23}$ Evangelista AT, Coppola KM, Furness G. Relationship between group JK corynebacteria and the biotypes of Corynebacterium genitalium and Corynebacterium pseudogenitalium. Can J Microbiol 1984;30:1052-7.

${ }^{24}$ Furness G, Evangelista AT. Infection of a non-specific urethritis patient and his consort with pathogenic species of non-specific urethritis corynebacteria, Corynebacterium genitalium n sp. $\mathbf{I n}$ vest Urol 1976;14:202-5.

Requests for reprints to: Dr R Bayston, Department of Paediatric Surgery, Institute of Child Health, 30 Guilford Street, London WCIN 1EH, England. 